\title{
Web-based Digital Agreement System for Freelancers: Case Study in Bangladesh
}

\author{
HUMAYRA AHMED \& ABDUL RAHMAN MAT* \\ Faculty of Computer Science and Information Technology, Universiti Malaysia Sarawak, 94300 Kota \\ Samarahan, Sarawak, Malaysia \\ *Corresponding authors: marahman@unimas.my
}

\begin{abstract}
Nowadays, many people are interested in working as a freelancer because it gives opportunities to people to choose their work according to their convenience. Currently, the people of Bangladesh are using a bidding or direct booking system for buying and selling freelance services. There are very limited opportunities for freelancers to promote their work. Therefore, the purpose of the proposed system is to provide a platform where freelancers can promote their skills and at the same time customers can post job offers and create an agreement with the freelancer. This agreement will create a bridge between the customer and the freelancer. It is hoped that the proposed system will provide a more convenient way for freelancers in Bangladesh to promote their skills and find freelance jobs.
\end{abstract}

Keywords: Agreement, freelancer, project bidding, web-based development

Copyright: This is an open access article distributed under the terms of the CC-BY-NC-SA (Creative Commons Attribution-NonCommercial-ShareAlike 4.0 International License) which permits unrestricted use, distribution, and reproduction in any medium, for non-commercial purposes, provided the original work of the author(s) is properly cited.

\section{INTRODUCTION}

Digital technology has become a part and parcel of our daily life. Computers, laptops, software, mobile devices and calculators are the most common digital gadgets that we use in our daily life. Today it is unimaginable to spend a single day in the world without technology. To keep up with other countries, the government of Bangladesh has taken an initiative to develop Bangladesh as a digital country by 2021 (Tasneem, 2019). It is the nation's dream to see Bangladesh as a digital country. Digital Bangladesh signifies that a step has been taken to integrate Information and Communication Technology in every aspect of life.

In today's world, most of the people are familiar with the term 'freelancer'. A freelancer is a person who sells work or services online by the hour, day or job to different companies and clients according to their convenience. It provides the opportunity to start earning from home by freelancing a skill that one already has. To be a part of this Digital Bangladesh vision 2021, a web-based agreement system for freelancers of Bangladesh would help them to enter into an online agreement with the customers for buying and selling services of different categories such as graphic design, web, video and animation, photography, writing and translation. In Bangladesh, people can use this platform and start earning money, as long as they have an internet connection. The ultimate objective of Digital Bangladesh is to make more and more digitalised services available at the doorstep of the people where possible.

Unemployment is one of the major problems in Bangladesh. According to Bangladesh Bureau of Statistics (BBS), currently, the percentage of unemployed people is 4.17 (Neazy, 2019). A major portion of this unemployment is attributed to educated youths. About $41 \%$ of the youths of Bangladesh were unemployed in 2013 (LFMEAB, 2019). Now, it has increased to 46\%. To overcome this problem, a goal has been set by the Bangladesh government to train 13,000 unemployed people in three specific ICT fields such as graphic design, web design and development, and digital marketing under the Professional Outsourcing Training Program. There are around 11,920 people who have already completed their training from the targeted range (Islam, 2018), but 
there is not enough job opportunity to employ them immediately. However, freelancing systems can provide the facility to utilize the skills that they have learned so that they can start earning money.

There are a few available Bangladeshi freelance websites (Touch IT Solutions, 2019, Hypertag Solution Ltd, 2015). Some of them are using a bidding system or direct order system for buying and selling services like other freelance websites that are available worldwide. People have problems using international freelancing platforms in Bangladesh because of some limitations such as not having permission to access PayPal and high foreign transaction fees. The proposed system will provide an agreement system to the users of Bangladesh where the freelancer and customer can interact directly. Thus, the challenge is to find a way to overcome all these difficulties and provide a system where people of Bangladesh can work according to their convenience.

The objective of this project is to design and to develop a web-based digital agreement system in which freelancers can sell services of different categories, besides to promote their skills. In addition, this system will enable a digital agreement for hiring freelancers or buying services.

This project will provide an agreement based freelancing system where freelancers can communicate with their clients and update the progress of their work through a digital agreement. It will facilitate the users with the opportunity to post job advertisements (AD) for hiring freelancers and at the same time to post service AD to promote freelancers' skills. This digital agreement helps the freelancers and customers to feel safe while buying and selling services, and both parties can also exchange feedback using the agreement. This system will keep a record of all agreements.

\section{Overview of Freelancers Digital Agreement System}

Web-based digital agreement system is an online system for the people (freelancer) of Bangladesh where users can post jobs and services from a single account (Bonar, 2010). A freelancer will be required to create an account to use this system. They will need to create an account by adding a username, password, and a valid phone number. After that, they can sign into the system and verify their phone number to become a valid user. Freelancers will not be able to post an advertisement or apply for a job without signing into the system. He or she will be able to provide other account details such as Google, Facebook on this account. In addition, the freelancer will be able to create their portfolio by adding their expertise and, work experience. Clients who want to hire freelancers will be able to post a job advertisement and freelancers who want to provide a service will be able to post a service advertisement. They also will be able to search for jobs or services by keyword or category.

After finding the freelancers or service, the client will create an agreement. To complete the agreement payment, users will be asked to verify their account and inform the administrator. On this agreement, the client and freelancer will be able to communicate with each other, monitor the progress of the work and exchange feedback. The system will keep a record of the posted advertisements and agreements. Clients and freelancers will also be able to communicate in the comments section. In addition, the clients will be able to claim a refund if the agreement is not completed. There will be a proper guideline for the users (clients and freelancers) so that the first-time users can easily use this system.

\section{MATERIALS \& METHODS}

\section{Requirements Analysis}

In order to develop a system which, fulfil user needs, gathering requirements are essential (Fitzgerald \& Russo, 2002; Gomaa, 2011). As shown as in Table 1, there are ten (10) requirements provided as a basis for the construction of the system. These requirements were collected from a series of discussions with freelancers and clients in Bangladesh via emails. Based on this list, both freelancers and clients should be requested to register in order to use the system. In addition, depending on the skills and services that they can provide, the freelancers can find related jobs by browsing the advertisements and, communicating with the clients until both parties agree with the terms. In addition, clients can rate the service provided by the freelancer while the freelancer can rate and send a feedback on the clients' facilities. 
Table 1. List of requirements for the Digital Agreement System

\begin{tabular}{ll}
\hline Req ID & Requirement description \\
\hline R01 & User should be prompted with login. \\
R02 & The system should be easy to use. \\
R03 & Enable users to find freelance jobs easily. \\
R04 & Enable clients to hire a freelancer. \\
R05 & Enable freelancers to promote their services. \\
R06 & Create a bond between clients and freelancers. \\
R07 & Providing clear guidelines about the system. \\
R08 & Agreement document should be enabled. \\
R09 & Facilitate the users with easy communication way within the system. \\
R10 & Provide an opportunity to give feedback on the service. \\
\hline
\end{tabular}

\section{System Design}

Modelling the system before it can be implemented is to assist both designers and developers to understand the physical and logical designs of the system to be developed. This design includes a context diagram, data flow diagrams, and entity relationship diagram (Howcroft \& Carroll, 2000).

\section{A. Context Diagram}

The general overview of the system is shown in Figure 1. The client needs to login to the system to use this system as shown in the diagram. Then the Client can post advertisements, search for services by keyword, create an agreement and gets request to complete payment and inform the Administrator. The Freelancer also needs to login to the system to use the system. After that, they can post advertisements, search for jobs by keyword, send job applications and send request to release their payment. Furthermore, both the Client and Freelancer can exchange feedback. Lastly, the Administrator will work at the backend in which he (or she) will get the agreement details. Once the agreement is created, the Administrator will be able to approve the payment and at the same time, to maintain the system.

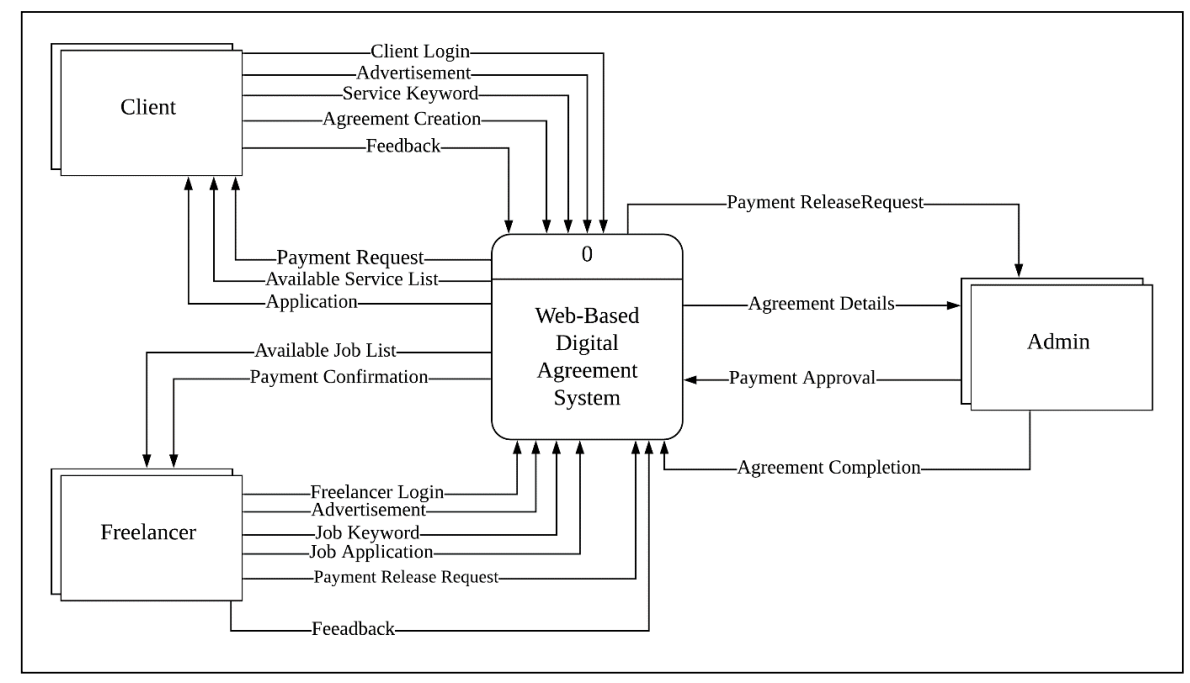

Figure 1. Sample of context diagram of the system 


\section{B. Data Flow Diagram}

The detail of all processes required for making sure the system is running smoothly is presented through Data Flow Diagrams. As shown in Figure 2 for developing Digital Agreement System for Freelancers, there are three (3) types of entities involved including Client who require the service, Freelancer who provide the service, and Admin who acts as a backend for getting the agreement details, to approve the payment and to maintain the system. In addition, there are seven (7) major processes to achieve the objective of the system, including Login, Post an AD, Find Job, Find Service, Send Application, Create Agreement, and Give Feedback. All the related data are stored in different five (5) data stores, such as Users, JobADs, Services, Applications, and Comments. As shown in Figure 3, the process Post an $A D$ is decomposed into the next level. This decomposition process involves five (5) processes, including Select AD Option, Post AD for Hiring Freelancer, View Job AD, Post AD for Giving Service, and View Service $A D$. Furthermore, this decomposition is connected to two (2) data stores including JobADs and Services data stores, respectively.

\section{Entity Relationship Diagram}

The Entity Relationship Diagram (ERD) represents a conceptual database as viewed by the end-user. ERDs depict the database's main components which are entities, attributes, and relationships. Three main entities are involved in the proposed system. They are Client, Freelancer and Admin. The detail of attributes for each data store is shown in Figure 4. There are five (5) data stores, which are consistent as presented in Figure 2 previously. Each data store is connected to each with different ordinality and cardinality, including zero-to-one, one-to-one, oneto-many, and many-to-many cardinality. Ordinality refers to the minimum number of times an instance in one entity can be associated with an instance in the related entity, while cardinality refers to the maximum number of times an instance in one entity can relate to instance of another entity. Each data store has a primary key to present a unique identity for each instance. As an example, a user who is a Client can post many job advertisements. Each job advertisement consists of jobid, title, posterid, job description, location, and budget. However, each job only can be done by one user (who is a Freelancer).

\section{RESULTS}

The Digital Agreement System for Freelancers was implemented using Sublime Text 3 as a code editor and XAMPP tool for web application development. This web application development server comes pre-installed with Apache web server, MySQL database, PHP, and Perl which helps to build an offline application with desired features and functions. It works perfectly on multiple platforms such as Linux, Windows, and Mac OS. As for this development, XAMPP phpMyAdmin has been used as relational database management system (Apache Friends, 2020).

\section{System Hierarchy}

The overall interfaces of Digital Agreement System for Freelancers are presented as in Figure 5. Based on this figure, there are sixteen (16) interfaces available including the Main Page, Create an account, Sign in, Post an $A D$, Find services, and Find jobs. For the Sign in module, the user will be required to verify their account. As for Post an AD, the Client (who is hiring) can accept the application from the Freelancers (who is giving a service) to book for a service. After a series of communications between Client and Freelancer, the agreement will be produced and signed by both type of users. In addition, both users can rate each other in a feedback which will be a future reference for other users. The Clients can view services posted by the Freelancers and book for the services which fulfil their requirements, while the Freelancers can send applications for the jobs posted by the Clients thru the advertisement.

\section{Agreement}

When the client accepts any job application or book any service, the agreement will be automatically created with a unique agreement ID, the current status of the agreement, agreement details, client's name, client's phone number, freelancer's name, freelancer's phone number, charge of the agreement, and summary of the agreement (Figure 6). The agreement will be added to the agreement list of the corresponding Client and Freelancer. After 
the payment has been made by the Client (depending on the amount of agreed), the agreement will be activated, and the Freelancer will start performing the job scope.

\section{Feedback}

Another important feature in this system is to allow both Client and Freelancer to rate each other. As shown in Figure 7, the Freelancer can rate the Client facilitation in score format ranging between 1 (very poor) until 5 (excellent). Without giving a score, the Client would not be able to release the balance of money to be paid for the Freelancer. At the other hand, the Client's score to the Freelancer is essential in order for the money to be received by the Freelancer. This is to make sure that both types of users exchange their feedback in order to complete the agreement.

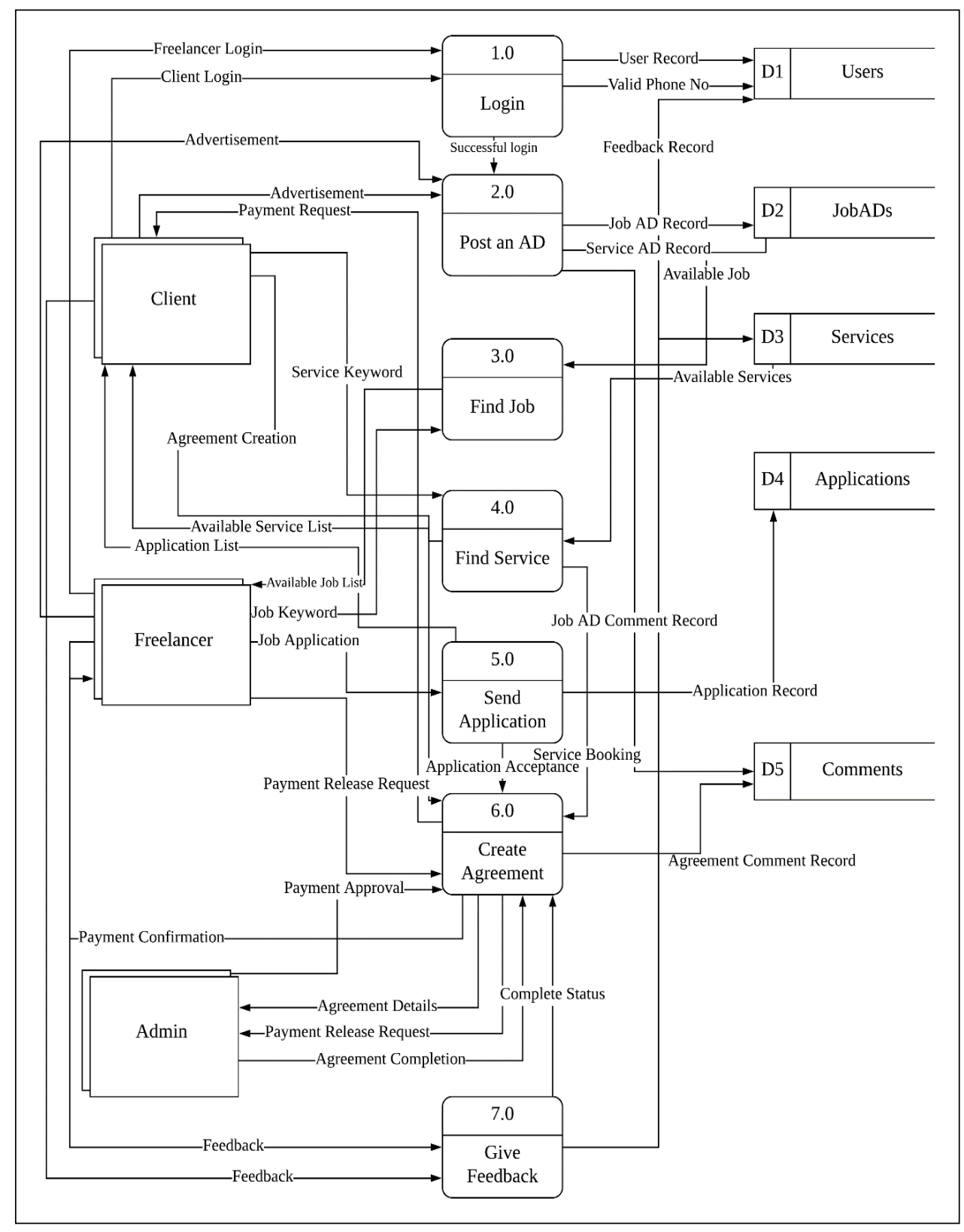

Figure 2. Sample of level-0 data flow diagram. 


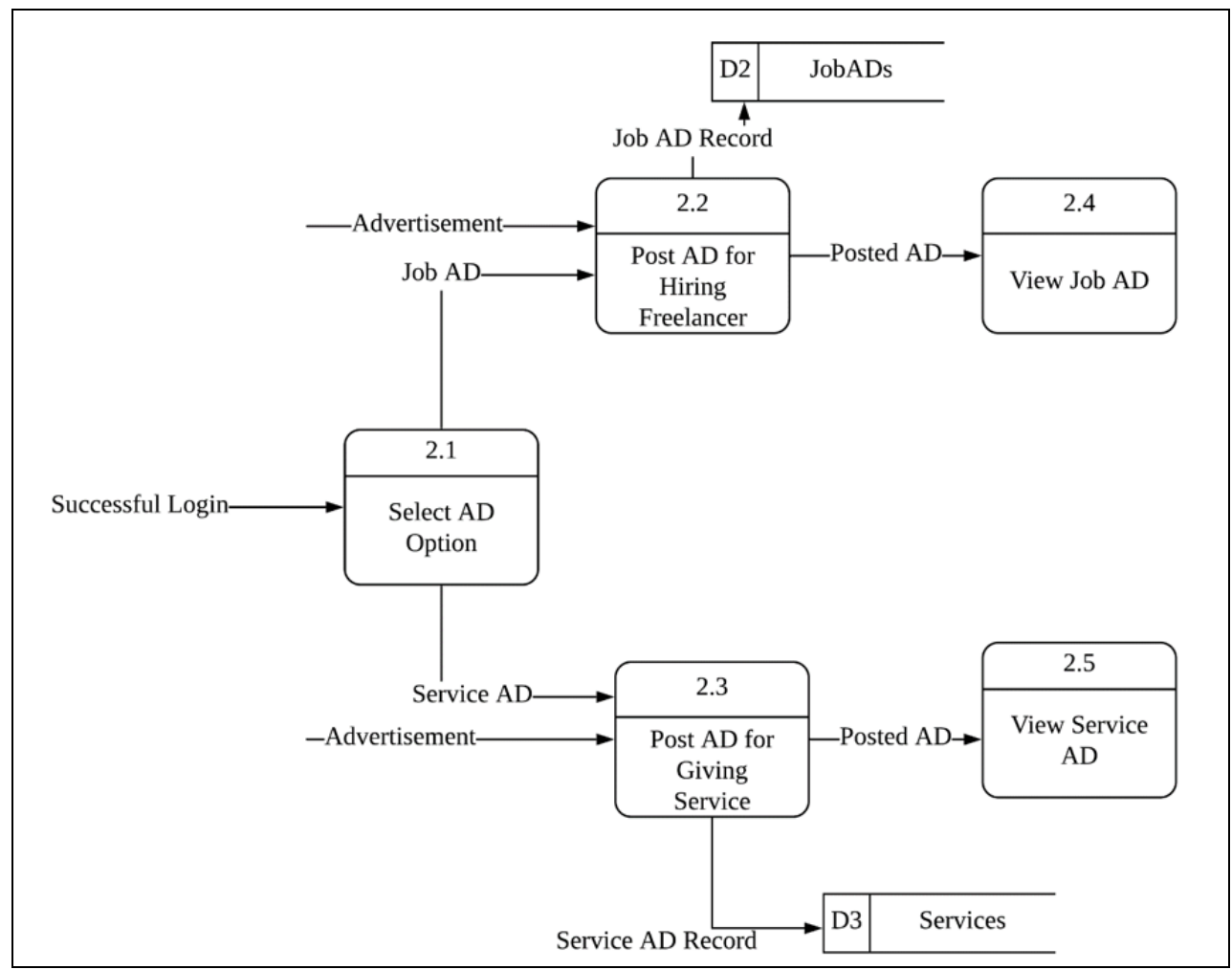

Figure 3. Sample of level-1 sub-process Post an AD

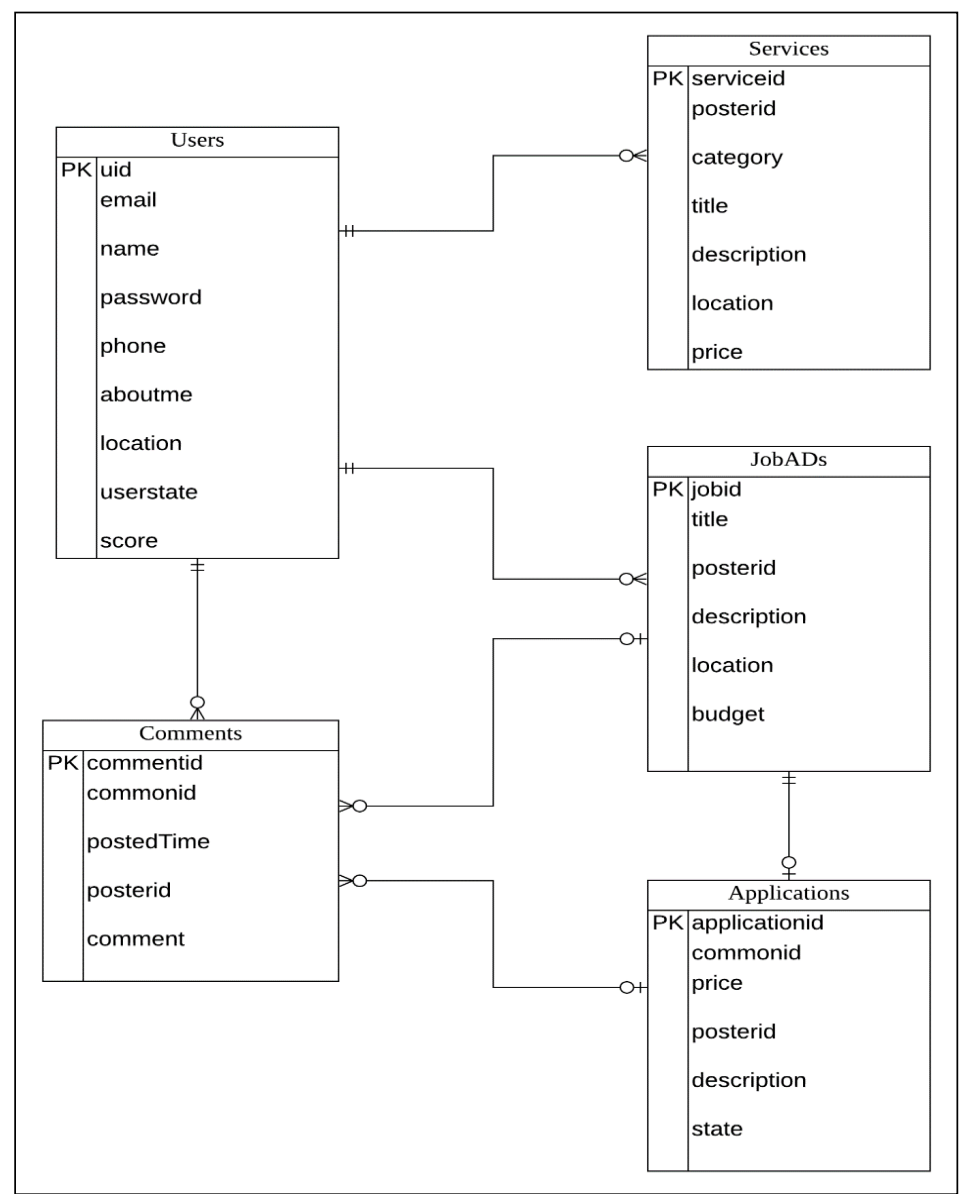

Figure 4. Sample of entity relationship diagram of the system. 


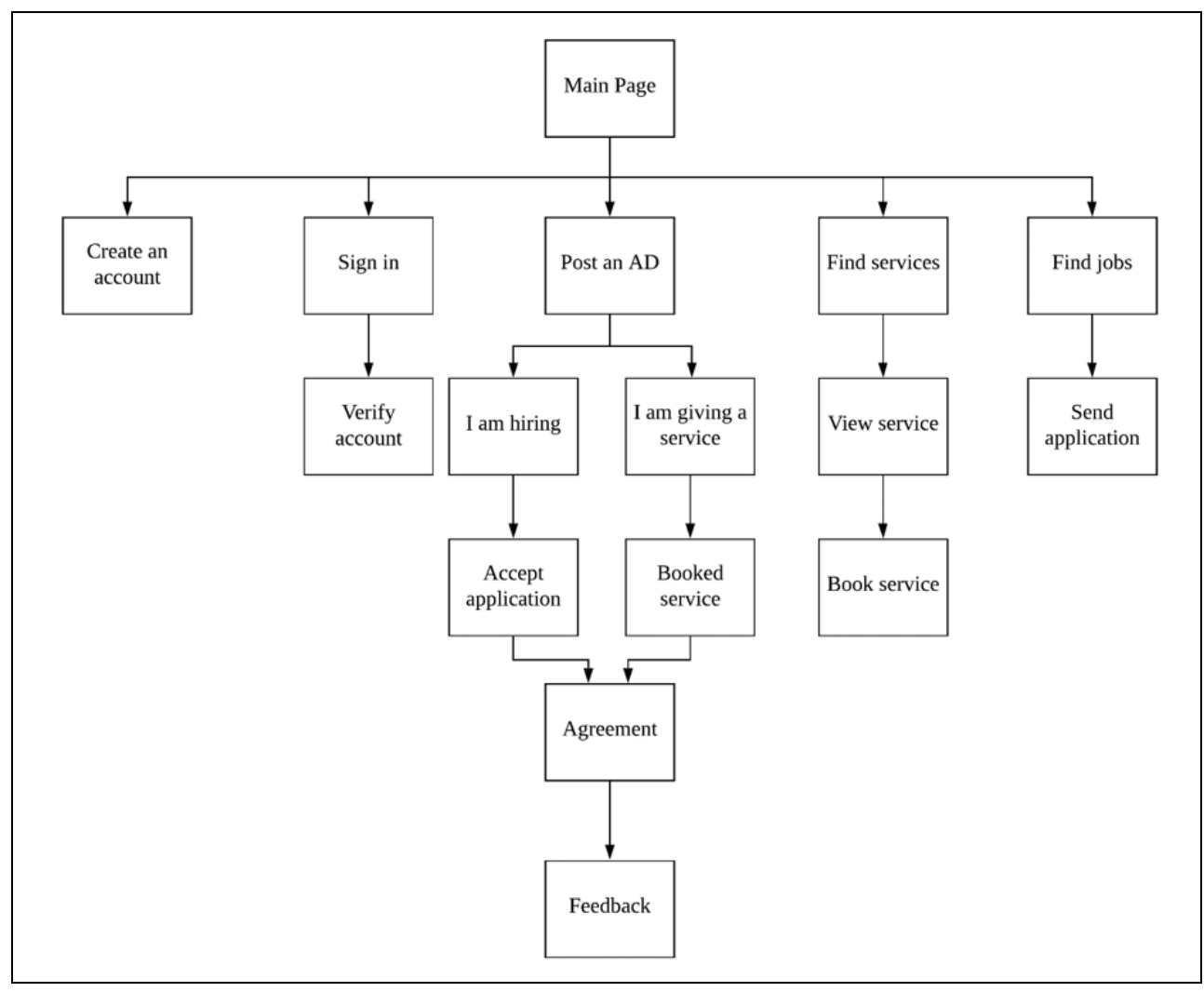

Figure 5. Hierarchical structure of the system

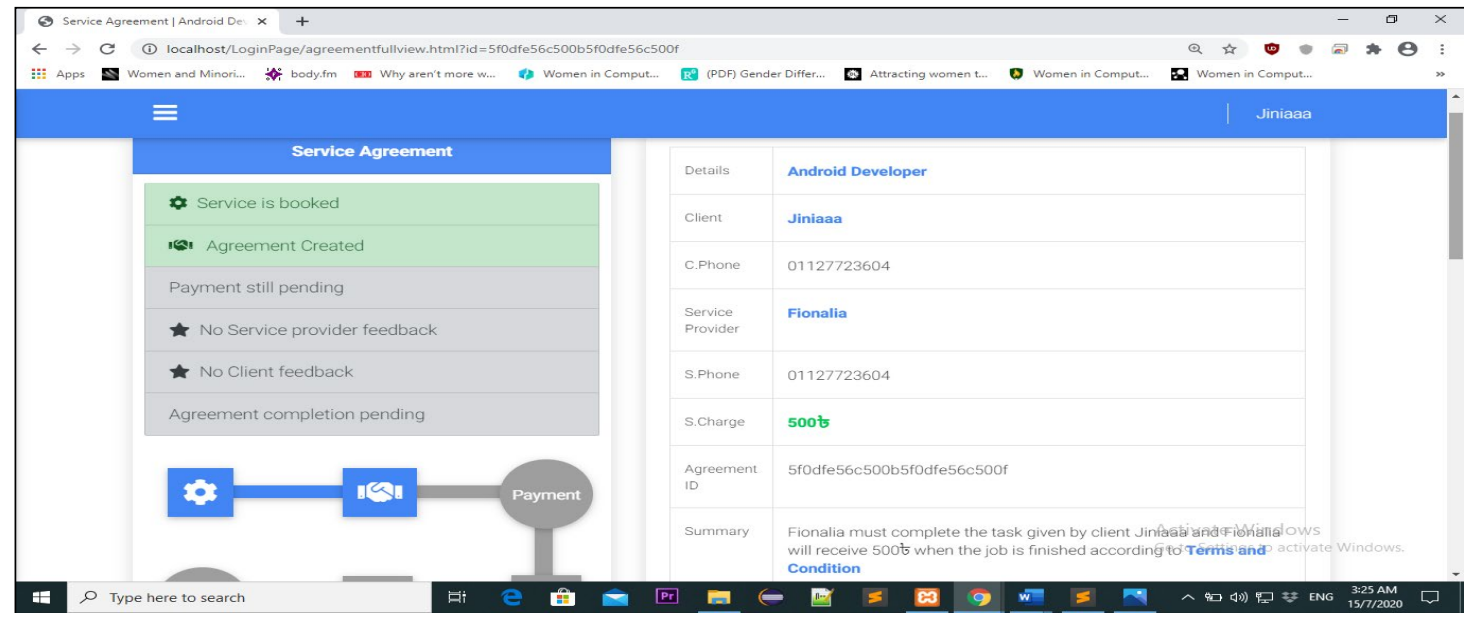

Figure 6. Sample interface for the agreement

\section{DISCUSSION}

The Digital Agreement System for Freelancers has been developed to facilitate the freelancers in Bangladesh to buy and sell services of different categories such as web, graphics and design, video and animation. In this system, users can book services or give services from the same account. If the user is Client which means he needs services, then he can post a $J o b A D$ or he can look for the required services in the Find Services option. If the user is a Freelancer which means he wants to provide services, then he can Post a Service AD or look for job in the Find jobs section. By posting a service AD they will be able to promote their skills to Clients. 


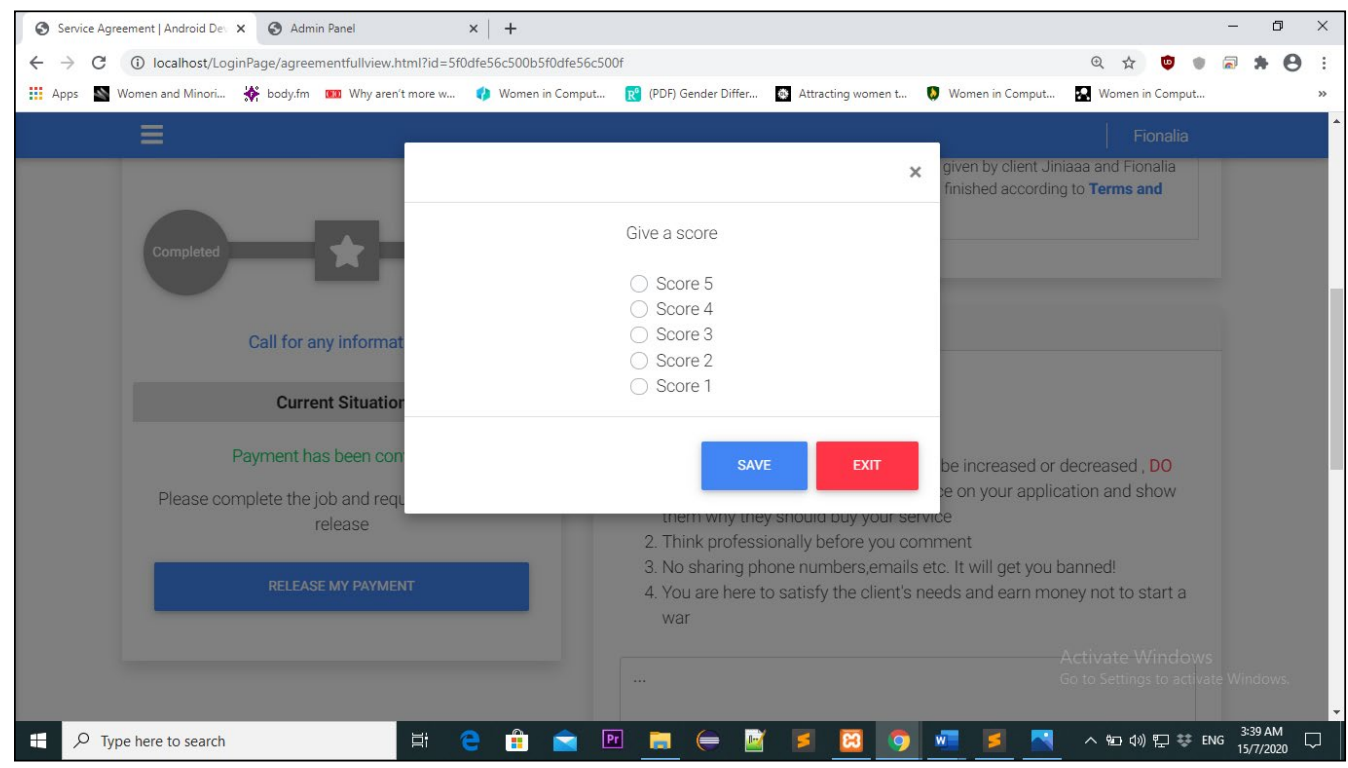

Figure 7. Sample interface for Freelancer to rate the Client.

When the Freelancers find any suitable job, they will be able to send an application for that job. Then the Client, who posted that job advertisement will be able to see the list of applications in the "People applied for this job" section. After that, if the client wants to accept any job application he can click on the "accept" button and the agreement will be created automatically. On the other hand, if the Client wants to book any service from the service advertisement, he can click on the "Book This Service" button and the agreement will be created automatically. Once the agreement is created, the Client will be asked to make payment and inform the Admin. The Admin will check the payment and activate the agreement and the Freelancer will start working on that job. After finishing the work, the customer and freelancer will exchange feedback and complete the agreement. Along the process, the Client, Freelancer and Admin will be able to see the current status of the agreement. By this procedure, the users will be able to buy and sell services in this system.

\section{User Acceptance Testing}

The "Web-based Digital Agreement System" was tested on 10 respective Bangladeshi clients in order to ensure the effectiveness and satisfaction of using the system. They were asked to explore the system from the start until the end with the questionnaires to be filled in. As shown in Figure 8, five elements were tested for effectiveness including, background canvas, font color and size, suitability of the icons and images used and button. Based on the result, on average, all respondents rated the effectiveness of the system to be either "Excellent" or "Good". In addition, all of them were satisfied with the availability of the system.

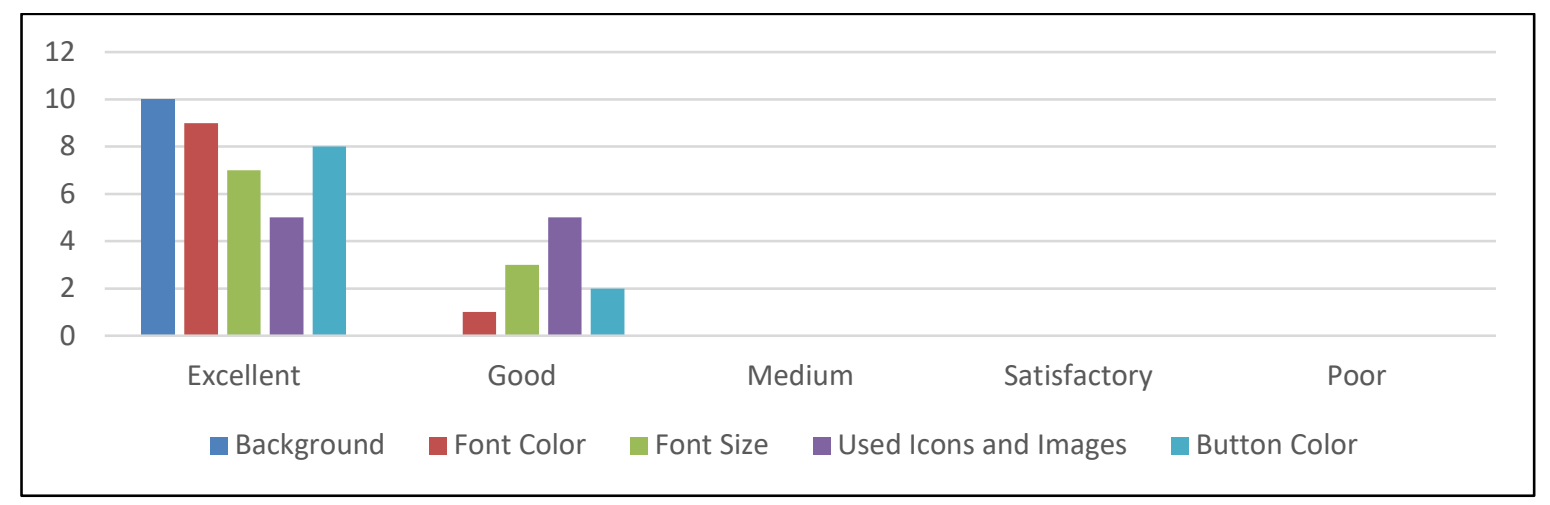

Figure 8. Evaluation chart for effectiveness of the system. 


\section{CONCLUSION}

As a conclusion, the development of this system, could help the freelancers of Bangladesh to buy and sell their services in an easy and convenient way. It offers the freelancers to give services in eight different categories such as graphics and design, web, video and animation, photography, digital, writing and translation, computer and mobile, and printing and digital media. Freelancers can also give services in categories other than that given. For any services which are not mentioned, the respective freelancers need to choose the category as 'other'. In addition, this agreement system will create a relationship between the client and freelancer whereby both parties will be able to communicate easily.

However, this system has some limitations. Firstly, the interface of the admin page has lack of facilities such as to edit or to update data directly from their page. At the moment, the admin has to log in using the different site (using phpMyAdmin) in order to access and to maintain the system. This is not feasible and requires a lot of works. Secondly, the currency that is used in this system, is Taka (Bangladesh currency) which limits its use. Different currencies can be added to this system to expand the use of this system worldwide. The other limitation of this system is in the matter of payment. At the moment, the payment needs to be approved manually which might slow down its working process.

In order to improve and to expand the use of this system widely, first and foremost, it is important to design a more effective admin page from where they can easily maintain the system. In addition, the scope of the system should be increased by implementing more related functions like creating notification module, direct messaging within the system and a login option for administrator. Secondly, in order to facilitate freelancers worldwide, the system should be able to allow currency exchange, such as in Dollar, Euro or other currencies. This will attract and create more jobs with relevant skills and services. Finally, since the Freelancers Digital Agreement system is developed for buying and selling services online, adding an online payment gateway is also possible in future system upgrades. If a payment gateway is added, the agreement can be automatically activated by using the unique agreement ID and this will reduce the administrative workload.

\section{REFERENCES}

Apache Friends. (2020). New XAMPP version with fixes for MariaDB and phpMyAdmin. Retrieved March 25 2020 from Apache Friends.

Bonar, S. (2010). The Freelance Marketplace Review. WhichLance.com.

Fitzgerald, B., \& Russo, N. (2002). Information systems development: Methods in action. London: McGraw-Hill. Gomaa, H. (2011). Software modelling and design: UML, use cases, patterns, and software architectures. America, NY: Cambridge University Press.

Howcroft, D., \& Carroll, J. (2000). A Proposed Methodology for Web Development. European Conference on Information Systems. AIS Electronic Library.

Hypertag Solutions Ltd. (2015). Belancer WORK FOR EVERYONE. Retrieved December 152019 from https:// belancer.com/

Islam, S. (2018). Digital Bangladesh a reality now. Retrieved December 152019 from https://www.dhakatribune. com/bangladesh/2018/07/11/digital-bangladesh-a-reality-now

LFMEAB (2019). Youth unemployment remains a big problem for Bangladesh. Retrieved December 122019 from https://lfmeab. org/youth-unemployment-remains-a-big-problem-for-bangladesh/

Neazy, S. N. (2019). Rise of the educated unemployed. Retrieved November 112019 from https://www. dhakatribune.com/opinion/op-ed/2019/06/28/rise-of-the-educated-unemployed

Tasneem, F. (2019). Digital Bangladesh is making progress. Retrieved November 112019 from https:// borgenproject.org/digital-bangladesh-is-making-progress/

Touch IT Solutions. (2019). ShadhinKaj. Retrieved December 152019 from https://shadhinkaj.com/ 